\title{
THE GENETICS OF THE BEE-LIKE PATTERNS OF MERODON EQUESTRIS
}

\author{
D. L. T. CONN \\ Departments of Zoology and Applied Entomology, Imperial College, \\ University of London
}

Received I6.ix.7 I

\section{INTRODUCTION}

Mrmetic polymorphism of insects has been most studied in tropical species (Sheppard, 1961 ; Ford, 1964; Rettenmeyer, 1970). In temperate latitudes the phenomenon is certainly less spectacular and appears to be less common in every sense. However, it is by no means absent. This communication reports a case which is at least as complex in the number of mimetic morphs as any tropical example analysed so far and which is characteristically temperate in that the models are bumble bees (Bombus and Psithyrus). Bumble bees hardly reach the tropics, whereas in the north temperate region they form a dominant group of large stinging insects.

The mimetic species studied is the Large Narcissus Bulb Fly, Merodon equestris Fab. (Syrphidae). It is apparently endemic in southern Europe, but the transport and cultivation of Narcisstus bulbs, in which the larvae feed, has carried it to North America, Australasia and Japan (Commonwealth Institute of Entomology, 1960). It was first reported in the U.K. in 1869 (Verrall, 1901).

A similar conspicuous polymorphism mimetic on bumble bees exists in another syrphid, Volucella bombylans L., which is also European but with a wider natural range. The variation of this species has been investigated in the U.S.S.R. and was found to depend upon two major gene loci (Gabritchevsky, 1924; Keeler, 1926). Although $M$. equestris is in the same family (Syrphidae) the genetic control I found was quite different and much more complex (Conn, 1971).

From a study of 150 crosses involving over 900 individuals the following has been revealed. The polymorphism depends upon six gene loci of which three are linked. Only one of these loci so far has revealed a multiple allele series. This is the locus concerned with ground colour. Besides showing epistasis inter se the other loci are all epistatic to ground colour in that they either allow full expression of ground colour or, as the alternative phenotype, superimpose various patterns of undiluted dark coloration. All the gene loci express themselves in various effects on the hairs of the dorsal parts of the thorax and abdomen. For the sake of continuity as far as possible the old varietal names have been retained and assigned to gene loci.

\section{Genetics}

(i) Ground colour

There are three major alleles at this locus and there is a simple dominance hierarchy (tables 1 and 2). The colour types are abbreviated to YOYO, 
TABLe 1

Ground colour

\begin{tabular}{|c|c|c|c|c|c|c|c|c|c|c|c|}
\hline \multirow[b]{2}{*}{ Cross type } & \multicolumn{11}{|c|}{ Progeny ratio } \\
\hline & \multirow{2}{*}{$\begin{array}{l}\text { Number of } \\
\text { crosses }\end{array}$} & \multicolumn{3}{|c|}{$0^{*}$} & \multicolumn{3}{|c|}{ ㅇ } & \multicolumn{3}{|c|}{ Overall } & \multirow{2}{*}{$\begin{array}{c}\text { Total } \\
\text { progeny }\end{array}$} \\
\hline$\sigma^{*}$ & & 1 & 2 & 3 & 1 & 2 & 3 & 1 & 2 & 3 & \\
\hline YOYO × YOYO & 7 & 39 & 3 & 4 & 18 & 5 & 3 & 57 & 8 & 7 & 72 \\
\hline YOYO $\times$ OOYY & 14 & 52 & 22 & 28 & 34 & 51 & 11 & 86 & 73 & 39 & 198 \\
\hline OOYY $\times$ YOYO & 5 & 13 & 9 & 10 & 17 & 14 & 3 & 30 & 23 & 13 & 66 \\
\hline YOYO $\times 0000$ & 3 & 18 & 0 & 11 & 10 & 0 & 10 & 28 & 0 & 21 & 49 \\
\hline OOOO × YOYO & 2 & 3 & 0 & 5 & 2 & 0 & 2 & 5 & 0 & 7 & 12 \\
\hline OOYY $\times$ OOYY & 5 & 0 & 9 & 4 & 0 & 20 & 0 & 0 & 29 & 4 & 33 \\
\hline OOYY $\times 0000$ & 1 & 0 & 1 & 0 & 0 & 2 & 0 & 0 & 3 & 0 & 3 \\
\hline OOOO $\times$ OOYY & 13 & 0 & 24 & 44 & 0 & 44 & 19 & 0 & 68 & 63 & 131 \\
\hline $0000 \times 0000$ & 6 & 0 & 0 & 46 & 0 & 0 & 29 & 0 & 0 & 75 & 75 \\
\hline
\end{tabular}

Class $1=$ YOYO. Glass $2=$ OOYY. Glass $3=0000$.

TABLE 2

Ground colour when validus, subvalidus or bulborum is expressed in at least one parent Progeny ratio

\begin{tabular}{|c|c|c|c|c|c|c|c|c|c|c|c|}
\hline Cross type & \multirow{2}{*}{$\begin{array}{l}\text { Number of } \\
\text { crosses }\end{array}$} & \multicolumn{3}{|c|}{$0^{*}$} & \multicolumn{3}{|c|}{ 우 } & \multicolumn{3}{|c|}{ Overall } & \multirow{2}{*}{$\begin{array}{c}\text { Total } \\
\text { progeny }\end{array}$} \\
\hline$\sigma$ & & 1 & 2 & 3 & 1 & 2 & 3 & 1 & 2 & 3 & \\
\hline YYO $\times$ YOYO & 11 & 68 & 2 & 8 & 31 & 0 & 13 & 99 & 2 & 21 & 122 \\
\hline YOYO $\times O C$ & 2 & 62 & 22 & 20 & 51 & 21 & 9 & 113 & 43 & 2 & 18 \\
\hline O) & 4 & 20 & 10 & 13 & 7 & 10 & 1 & 27 & 20 & 1 & 61 \\
\hline YYO & 3 & 11 & 0 & 6 & 5 & 0 & 4 & 16 & 0 & 10 & 26 \\
\hline OO & 4 & 0 & 10 & 8 & 0 & 6 & 11 & 0 & 16 & 9 & 25 \\
\hline OOC & 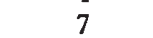 & 0 & 18 & 43 & 0 & 26 & 17 & 0 & 44 & 60 & 104 \\
\hline YOYO $\times$ MASKED & 26 & 108 & 14 & 21 & 21 & 33 & 14 & 129 & 47 & 35 & 211 \\
\hline OOY & 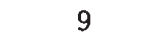 & 20 & 10 & 4 & 0 & 11 & 0 & 20 & 21 & 4 & 45 \\
\hline OOOO $\times$ MASKED & 11 & 33 & 30 & 24 & 0 & 28 & 11 & 33 & 58 & 35 & 126 \\
\hline
\end{tabular}

Class $1=$ YOYO. Class $2=$ OOYY. Class $3=0$ OOOO.

OOYY and OOOO, YOYO being dominant to OOYY and OOOO, and OOYY being dominant to OOOO. The colour code refers to the coloration progressing from the anterior of the thorax to the abdomen tip. For example, YOYO has a yellow haired thorax with an orange interalar band, a yellow anterior abdomen and an orange abdomen tip (see fig. 1). The anterior abdomen is the second abdominal segment and the abdomen tip is composed of the third and fourth segments. The first segment is overshadowed by the scutellum and the second segment, and is not very hairy. Segments after the fourth are withdrawn into the abdomen and are concerned with the genitalia. OOYY has an all orange thorax and an all yellow abdomen and $\mathrm{OOOO}$ is entirely orange.

There are variants within the above categories as illustrated. Genetically with respect to the other categories the variants behave in the same way as the standard type. The patterns give no hint as to why this grouping holds, but the genetics of the variants is being analysed. There are differences other than those of pure banding in the colour patterns of the groups, particularly between YOYO and the other two groups and this together with the presence of variants suggests the existence of "supergenes". 


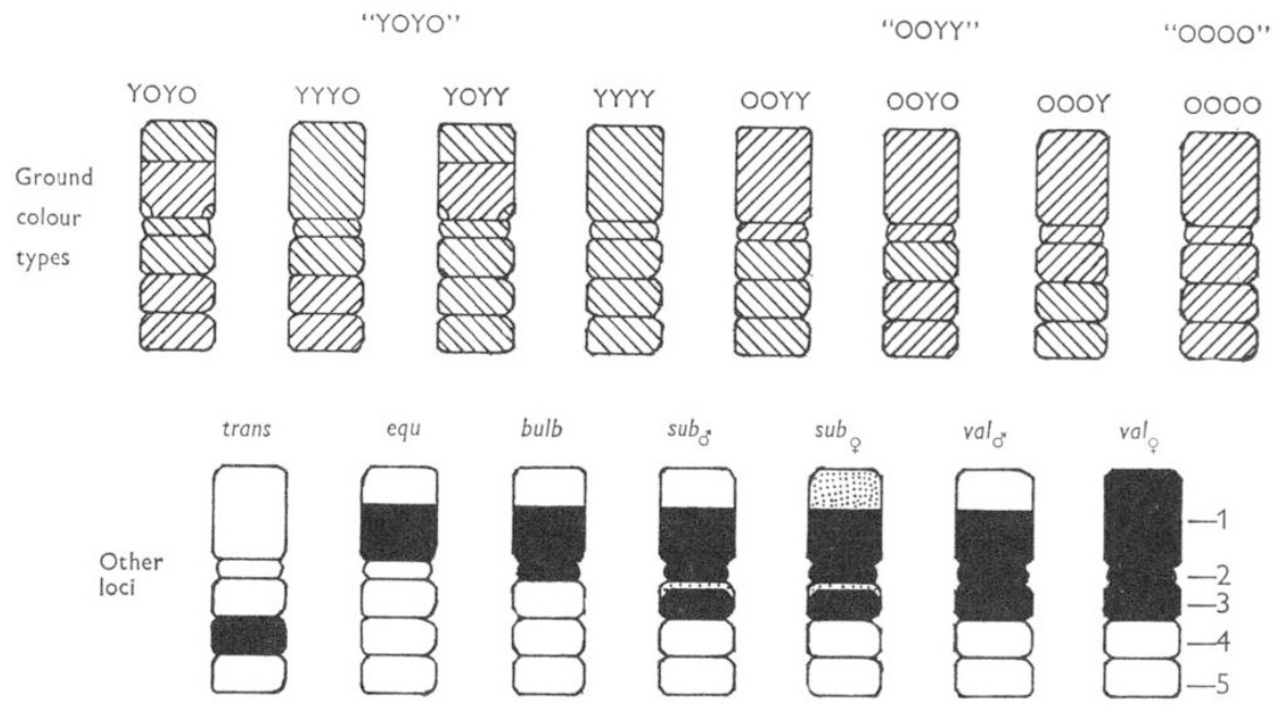

FIG. 1.-To show the effects of the different gene loci (each locus is illustrated in isolation). YOYO, OOYY, OOOO indicate major alleles at the ground colour locus. yoyo, yyyo, etc., indicate actual colour patterns from the anterior of the thorax to the posterior of the abdomen. $\quad$ trans $=$ Transversalis. equ $=$ Equestris. $\quad$ bulb $=$ Bulborum. sub $\delta=$ Subvalidus male. $\quad s u b q=$ Subvalidus female. val $\delta=$ Validus male. val $q=$ Validus female. $1,2=$ Components of thorax. $2=$ Scutellum. $3-5=$ Components of abdomen. $3=$ Second abdominal segment. $4=$ Third abdominal segment. $5=$ Fourth abdominal segment. $=$ Yellow. $=$ Orange. $\square=$ Black. $:::$ : $=$ Black hairs mixed with ground coloration. $\square=$ Ground coloration visible.

\section{(ii) Transversalis}

Contrary to a previous suggestion of sex-linkage (Hodson, 1932), this is an autosomal locus with sex-limited effect. (In the female one allele superimposes on ground colour a black band on the third abdominal segment.)

The expression of this gene is exceptional in that besides being darkened the hairs are reduced in size and this exposes the black cuticle underneath. Expression, however, is variable so that dominance is not clear and identification can occasionally be difficult (table 3 ).

\section{TABLE 3}

Transversalis

\begin{tabular}{|c|c|c|c|c|}
\hline \multirow[b]{2}{*}{$\begin{array}{l}\text { Gross type } \\
\text { ㅇ only }\end{array}$} & \multirow[b]{2}{*}{ Number of crosses } & \multicolumn{2}{|c|}{$\begin{array}{c}\text { Progeny ratio } \\
\text { o only }\end{array}$} & \multirow[b]{2}{*}{ Total progeny } \\
\hline & & 1 & 2 & \\
\hline Mother trans & 72 & 233 & 193 & 426 \\
\hline Mother non-trans & 82 & 183 & 313 & 496 \\
\hline
\end{tabular}

trans $=$ Transversalis. Class $1=$ Transversalis. Class $2=$ Non-transversalis.

\section{(iii) Equestris}

The presence of a black interalar band on the thorax is dominant to its absence (tables 4 and 5). This band is broadly similar in position to the orange interalar band of YOYO (see fig. 1). 
TABLE 4

Equestris

\begin{tabular}{|c|c|c|c|c|c|c|c|c|}
\hline \multirow[b]{2}{*}{ Cross type } & \multicolumn{8}{|c|}{ Progeny ratio } \\
\hline & \multirow{2}{*}{$\begin{array}{c}\text { Number of } \\
\text { crosses }\end{array}$} & \multicolumn{2}{|c|}{$\sigma^{\pi}$} & \multicolumn{2}{|c|}{ q } & \multicolumn{2}{|c|}{ Overall } & \multirow{2}{*}{$\begin{array}{c}\text { Total } \\
\text { progeny }\end{array}$} \\
\hline 훙 & & 1 & 2 & 1 & 2 & 1 & 2 & \\
\hline$E q u \times E q u$ & 2 & 9 & 4 & 5 & 1 & 14 & 5 & 19 \\
\hline Equ Narc & 7 & 13 & 16 & 17 & 27 & 30 & 43 & 73 \\
\hline $\mathcal{N a r c} \times E q u$ & 11 & 37 & 44 & 50 & 38 & $88 *$ & 82 & 170 \\
\hline Narc $\times$ Narc & 34 & 0 & 221 & 0 & 146 & 0 & 367 & 367 \\
\hline
\end{tabular}

* = sex of one insect not determined.

$E q u=$ Equestris or equestris-transversalis.

Narc $=$ Narcissi or transversalis.

Class $1=$ Equestris or equestris-transversalis.

Class $2=$ Narcissi or transversalis.

TABLE 5

Equestris when at least one of the parents is validus, subvalidus or bulborum

Progeny ratio

\begin{tabular}{|c|c|}
\hline Cross type & \\
\hline o & crosses \\
\hline Val $\times V$ & 3 \\
\hline Val $\times E q u$ & 4 \\
\hline$E q u \times V a l$ & 2 \\
\hline Val $\times$ Narc & 5 \\
\hline Narc $\times$ Val & 12 \\
\hline
\end{tabular}

\begin{tabular}{|c|c|c|c|c|c|c|c|c|c|}
\hline & \multicolumn{2}{|c|}{$\sigma^{*}$} & \multicolumn{3}{|c|}{ q } & \multicolumn{3}{|c|}{$\overrightarrow{\text { overall }}$} & \multirow{2}{*}{$\begin{array}{r}\text { Total } \\
\text { progeny }\end{array}$} \\
\hline 1 & 2 & 3 & 1 & 2 & 3 & 1 & 2 & 3 & \\
\hline 12 & 4 & 1 & 25 & 1 & 3 & 37 & 5 & 4 & 46 \\
\hline 8 & 1 & 3 & 5 & 4 & 1 & 13 & 5 & 4 & 22 \\
\hline 6 & 1 & 1 & 1 & 5 & 1 & 7 & 6 & 2 & 15 \\
\hline 11 & 3 & 5 & 19 & 11 & 2 & 30 & 14 & 7 & 51 \\
\hline 53 & 38 & 17 & 50 & 32 & 15 & 103 & 70 & 32 & 205 \\
\hline
\end{tabular}

$V a l=$ Validus, subvalidus, bulborum and transversalis derivatives of these types.

Class 1 =Validus, subvalidus, bulborum and transversalis derivatives of these types.

Class $2=$ Equestris or equestris-transversalis.

Class $3=$ Narcissi or transversalis.

Equ and Narc as in table 4.

\section{(iv) Bulborum}

The presence of a dark thoracic band is dominant to its absence (table 6). The dark band is similar in position to that produced by equestris except that it extends further back to include the scutellum. The gene is definitely not allelic to equestris.

\section{(v) Modifier $U$}

When the dominant allele of bulborum is present the dominant allele of this locus extends the darkened areas (table 6). There are some differences between the sexes in the amount of darkening. In the male the second abdominal segment possesses mixed coloured and black hairs, usually in a definite pattern with the posterior and outside of the segment being blacker than the anterior and median parts. In the female the anterior of the thorax is also darkened to an extent that is somewhat variable. The colour type produced by the combination of bulborum and modifier $\mathrm{U}$ is conveniently called subvalidus. 


\section{(vi) Modifier $V$}

This modifier gene in conjunction with the dominant alleles of bulborum and the modifier $U$ darkens the coloration further (table 6) in areas already partly darkened by the modifier $U$ to produce the colour type validus. In the male the second abdominal segment is black except for a few hairs on the anterior border and in the female the second abdominal segment and the anterior of the thorax are completely black. This modifier enhances the sex-limited characters expressed by the modifier $U$.

TABLE 6

Validus, subvalidus and bulborum

Progeny ratio

$\begin{array}{lc}\text { Cross type } & \begin{array}{c}\text { Number of } \\ \text { crosses } \\ \text { Val } \times \text { Val }\end{array} \\ \text { Val } \times \text { Sub } & 2 \\ \text { Sub } \times \text { Val } & 6 \\ \text { Sub } \times \text { Bulb } & 1 \\ \text { Bulb } \times \text { Sub } & 1 \\ \text { Val } \times \text { Other } & 23 \\ \text { Other } \times \text { Val } & 37 \\ \text { Sub } \times \text { Other } & 12 \\ \text { Bulb } \times \text { Other } & 5 \\ \text { Other } \times \text { Bulb } & 8 \\ \text { Other } \times \text { Other } & 56\end{array}$

\begin{tabular}{|c|c|c|c|c|c|c|c|c|c|c|c|c|}
\hline & & & & & . & & & & $\mathrm{Ov}$ & rall & & \\
\hline 1 & 2 & 3 & 4 & 1 & 2 & 3 & 4 & 1 & 2 & 3 & 4 & \\
\hline 36 & 8 & 0 & 6 & 43 & 1 & 5 & 8 & 79 & 9 & 5 & 14 & $\begin{array}{c}\text { otal pro } \\
107\end{array}$ \\
\hline 10 & 8 & 0 & 3 & 9 & 7 & 0 & 6 & 19 & 15 & 0 & 9 & 43 \\
\hline 14 & 0 & 0 & 6 & 15 & 0 & 3 & 5 & 29 & 0 & 3 & 11 & 43 \\
\hline 0 & 0 & 0 & 1 & 1 & 0 & 3 & 1 & 1 & 0 & 3 & 2 & 6 \\
\hline 3 & 0 & 0 & 0 & 2 & 0 & 0 & 0 & 5 & 0 & 0 & 0 & 5 \\
\hline 45 & 38 & 6 & 64 & 77 & 18 & 16 & 53 & 122 & 56 & 22 & 117 & 317 \\
\hline 59 & 34 & 7 & 93 & 112 & 5 & 2 & 93 & 171 & 39 & 91 & 186 & 405 \\
\hline 8 & 20 & 10 & 37 & 3 & 12 & 16 & 26 & 11 & 32 & 26 & 63 & 132 \\
\hline 0 & 6 & 1 & 5 & 1 & 3 & 3 & 4 & 1 & 9 & 4 & 9 & 23 \\
\hline 12 & 7 & 8 & 29 & 1 & 3 & 15 & 20 & 13 & 10 & 23 & 49 & 95 \\
\hline 0 & 0 & 0 & 355 & $1 *$ & 0 & 0 & 294 & $1^{*}$ & 0 & 0 & 649 & 650 \\
\hline
\end{tabular}

Val $=$ Validus or validus-transversalis

$S u b=$ Subvalidus or subvalidus-transversalis

Bulb $=$ Bulborum or bulborum-transversalis

Other = Other types-equestris, transversalis, narcissi, etc.

Class $1=$ Validus or validus-transversalis

Class 2 = Subvalidus or subvalidus-transversalis

Class $3=$ Bulborum or bulborum-transversalis

Class $4=$ Other types-equestris, transversalis, narcissi, etc

The complete colour pattern corresponding to any genetic constitution is easily built up by superimposing the colour patterns shown in fig. 1 . For example, a female yoyo/ooyy, tt, ee, $\mathrm{Bb}, \mathrm{Uu}, \mathrm{Vv}$ which might be described as validus YOYO is phenotypically a black fly with an orange tail. It would be indistinguishable from a female validus OOOO. Male validus YOYO and validus $\mathrm{OOOO}$ are quite distinct as the anterior of the thorax is not black. But in both male and female the state of the equestris locus could not be ascertained in such bulborum flies except by progeny testing.

Linkage studies are greatly hampered by the epistasic interactions that eliminate many families from consideration. Nevertheless, linkage has been detected between the requestis, bulborum and ground colour loci. My results (Conn, 1971) suggest about 20-25 per cent. recombination between equestris and bulborum, 15-20 per cent. between bulborum and ground colour and about 30 per cent. between equestris and ground colour. Thus the order of mention above is the order on the chromosome. 


\section{Mimiary}

Mimetic relationships of the colour types to various common species of Bombus are shown in table 7. Such a table gives an indication of how well the variation covers the range of important models but does not in itself indicate the relative success of the different colour types as the various species of bumble bees have different distributions and some have colour variants also. Further complexity is suggested by the fact that, although bumble bees have a large mimetic following among other insects, they are themselves far from adopting a common pattern through Mullerian mimicry. In some species the females are not even mimicked by their males. Although lacking the protection of a sting, the male bumble bee is often more flamboyantly coloured than the corresponding queen and worker. Table 7 shows, nevertheless, that there are common bumble bee models for most of the common morphs of $M$. equestris. For a more critical assessment simultaneous sampling of models and mimics will be necessary.

With bumble bees themselves so varied possibly some predators come to treat all stripey hairy flies with caution so that morphs that apparently lack close models (such as the morph equestris in Britain) still have some protection. This would weaken any tendency for selection to tighten linkages and create supergenes. Such generalisation (or lack of discrimination) by predators might help to explain the weak linkages found in Merodon -so far as I know no similarly weak linkages have been recorded hitherto in studies of mimetic polymorphism. However, against this tentative hypothesis two considerations must be added.

One is that a more "classical" situation, suggestive of supergenes, seems to exist in the other bee-mimicking polymorphic Syrphid that has been investigated. In Volucella bombylans, as shown by Gabritchevsky (Keeler, 1926), one locus produces sweeping changes in the entire pattern. The dominant allele gives an excellent mimic of the black-with-red-tail pattern of Bombus lapidarius. The other allele when homozygous gives a paler stripey pattern which may be white-tailed or red-tailed depending on the state of a second locus. This is apparently not linked to the first and is epistatic to it in that the "lapidarius" morph always has a red tail. Apart from this epistasis, white is dominant to red, and the resulting stripey morphs have generalised resemblance to bees like $B$. hortorum and $B$. pratorum respectively. Thus $V$. bombylans mimics three common bee patterns, but, unlike $M$. equestris (and various other syrphids such as Criorhina berberina and Eristalis intricaria), it fails to mimic another of the commonest-the pale and basically unstripey pattern typified by $B$. pascuorum. On the other hand $V$. bombylans produces no non-mimetic forms.

The other point against generalised avoidance as the explanation of weak linkages and the existence of non-mimetic morphs is the occurrence of a predictable linkage disequilibrium. If $M$. equestris is a Batesian mimic, and if predators are not deceived by generalised resemblance and in any particular area only a limited number of bumble bee species are common it should be possible to show that selection is favouring the most mimetic morphs. The intensity of selection would be indicated by the degree of linkage disequilibrium. In fact, in the population that I have examined for several years a linkage disequilibrium favouring the better mimics has been found. This is being investigated. 


\section{TABLE 7}

The resemblance of the morphs of Merodon equestris Fab. to some common species of bumble bees Some common bumble bees

Morphs of Merodon Equestris

Narcissi YOYO

OOYY

OOOO

Transversalis YOYO

OOYY

OOOO

Equestris YOYO

OOYY

OOOO

Equestris-transversalis YOYO

OOYY

OOOO

Bulborum YOYO
OOYY
OOOO

Bulborum-transversalis YOYO

OOYY

OOOO

Subvalidus male YOYO

OOYY

0000

Subvalidus female YOYO

OOYY

OOOO

Subvalidus-transversalis YOYO

OOYY

OOOO

Validus male YOYO

OOYY

OOOO

Validus female Orange tail

Yellow tail

Validus-transversalis Orange tail

Yellow tail

Good resemblance

Poor resemblance

Fair resemblance

Others

Resemblance to male bumble bees only is indicated by an open figure.

Note. Non-British continental bees may provide relevant models for a few of the $M$. equestris morphs which appear non-mimetic in the above table. Such bees are omitted due to lack of evidence on distribution and abundance (Alford, 1971). 


\section{Summary}

1. The genetics of the mimetic colour polymorphism shown in $M$. equestris has been extensively studied. There are 34 basic colour types which behave genetically as if there are six gene loci listed as follows:

(i) Ground colour. With three alleles determines the distribution of orange and yellow colouration over the thorax and abdomen.

(ii) Transversalis. A dark abdominal band in the female only.

(iii) Equestris. Produces a dark thoracic band.

(iv) Bulborum. Darkens all the thorax except the anterior.

(v) Modifier U. Extends the area of darkening of bulborum. There is some sex-limited expression.

(vi) Modifier V. In conjunction with bulborum and the modifier $\mathrm{U}$ this blackens already sombre coloured segments.

2. Three of the loci show some indication of linkage; equestris, bulborum and ground colour (in that order). However, linkage data are very scant and difficult to unravel because of locus-locus interactions.

3. Mimicry has not been studied in the field but lists of like colour types have been drawn up and their implications with respect to $M$. equestris and the other bee-mimicking syrphid $V$. bombylans discussed.

Acknowledgments.-I thank Professor T. R. E. Southwood for facilities, Dr W. D. Hamilton for helpful criticism, and the Agricultural Research Council for financial support.

\section{REFERENCES}

ALFORD, D. v. (1971). Bumble bee distribution maps scheme: progress report for 1970 . Bee World, 52, 55-56.

COMMONWEALTh INSTITUTE of ENTomology (1960). Distribution maps of pests. Series $A$ (Agricultural), No. 120. London.

ConN, D. L. T. (1971). The genetics and biology of the large narcissus bulb fly, Merodon equestris Fab. Ph.D. thesis, University of London.

FORD, E. B. (1964). Ecological Genetics. Pp. xv+335. London: Methuen.

GABRITCHEVSKY, E. (1924). Farbenpolymorphismus und Vererbung mimetischer Varietäten der Fliege Volucella bombylans und anderer " hummelähnlicher " Zweiflügler. Zeitschrift fur Induktive Abstammungs- und Vererbungslehre (now Molecular and General Genetics), 32, 321 353. Berlin: Springer.

Hodson, w. E. (1932). The large narcissus bulb fly, Merodon equestris Fab. (Syrphidae). Bulletin of Entomological Research, 23, 429-448. London: Commonwealth Institute of Entomology.

KEELER, C. E. (1926). Recent work by Gabritchevsky on the inheritance of color varieties in Volucella bombylans. Psyche, 33, 22-27. Cambridge, Mass., U.S.A.

RETTENmeyer, C. w. (1970). Insect Mimicry. Annual Review of Entomology, 15, 43-74. Palo Alto, California.

SHEPPARD, P. M. (1961). Some contributions to population genetics resulting from the study of the Lepidoptera. Advances in Genetics, 10, 165-216. New York and London: Academic Press.

Verrall, G. H. (1901). British Flies, Volume VIII; Platypezidae, Pipunculidae and Syrphidae. Pp. 691+121 (Appendix). London: Gurney and Jackson. 